\title{
Can kangaroo care help newborns with neonatal abstinence syndrome? Case report
}

\author{
Susan M. Ludington-Hoe ${ }^{1}$, Amel M. Abouelfettoh *2,3 \\ ${ }^{1}$ FBP School of Nursing, Case Western Reserve University, Cleveland OH, United States \\ ${ }^{2}$ Faculty of Nursing, Cairo University, Cairo, Egypt \\ ${ }^{3}$ College of Nursing, KSAUHS, Al Ahsa, Kingdom of Saudi Arabia
}

Received: June 22, 2015

DOI: $10.5430 /$ cns.v3n $4 p 44$
Accepted: August 2, 2015

URL: http://dx.doi.org/10.5430/cns.v3n4p44

\begin{abstract}
Neonatal abstinence syndrome (NAS) is on the rise and NAS newborns are very agitated. Because Kangaroo Care (KC) soothes newborns, we wanted to know what NAS newborns' responses to KC were and how long mothers spontaneously offered KC. A case study design was used and two mother-newborn dyads were recruited by convenience sampling to have Modified Neonatal Abstinence Syndrome Scoring System score and length of KC measured when mothers were with their newborns. Modified Neonatal Abstinence Syndrome Scoring System scores did not decrease with one hour of KC, but did with three or more hours of continuous KC. Medications were regularly administered throughout. One mother provided 60-70 minutes of KC each time and the other mother provided 80 minutes- 11 hours of $\mathrm{KC}$. KC may be a supportive therapy for withdrawing newborns.
\end{abstract}

Key Words: Neonatal abstinence syndrome, Kangaroo care, Case report

\section{INTRODUCTION}

The number of infants with neonatal withdrawal syndrome in USA went from 7,653 in 1995 to 11,937 in $2008,^{[1]}$ and from 1/1,000 live births in 2000 to more than $3 / 1,000$ live births in 2009 (more than 13,000 US infants had Neonatal abstinence syndrome $[\mathrm{NAS}]),{ }^{[2]}$ constituting $55 \%-95 \%$ of opioid-exposed newborns. ${ }^{[1]}$ Hospital charges for treating NAS newborns soared from $\$ 190$ million to $\$ 720$ million between 2000 and 2009. ${ }^{[2]}$ The severity of NAS ranges between mild, with few (14.9\%) newborns needing treatment ${ }^{[3]}$ and severe, with $57 \%^{[4]}$ to $91 \%{ }^{[5]}$ of newborns needing pharmacologic treatment. When manifestation of NAS symptoms results in a Modified Neonatal Abstinence Scoring System (the predominant tool used in the United States ${ }^{[6]}$ score of 8 or more over two consecutive intervals). NAS is diagnosed and medications are administered to reduce agitation, minimize respiratory difficulties, improve feeding behavior, and console newborns so they can rest and sleep. Despite medication and supportive (non-pharmacologic) treatments, many opioid-exposed newborns with treated NAS have lower limb hypertonia, jerky movements and jitteriness that last 3-9 months, even though their development usually appears normal. $^{[7]}$

One supportive therapy that has not been applied to newborns with NAS is Kangaroo Care (KC). KC may be helpful in reducing NAS severity because of its physiologicallystabilizing, behaviorally-calming, and sleep-inducing effects in newborn who does not have NAS. ${ }^{[8-10]}$ But, KC may not be helpful because it is a source of multisensory stimulation, and multisensory stimulation has been shown to increase the severity of NAS. ${ }^{[11]}$ In addition, the substance abusing mother's tolerance of $\mathrm{KC}$ is unclear because one report re-

\footnotetext{
*Correspondence: Amel M. Abouelfettoh; Email: amelmoataz@ hotmail.com; Address: College of Nursing, KSAUHS, P.O. Box 2477, National Guard Health Affairs, Al Ahsa, 31982, Kingdom of Saudi Arabia.
} 
lated that five substance-abusing mothers tolerated only 15 minutes of $\mathrm{KC}$ with their preterm newborns and thought that $\mathrm{KC}$ was too intense. ${ }^{[12]}$ Another study reported that substance abusing mothers participating in 30 minutes of $\mathrm{KC}$ at birth as part of Baby Friendly requirements reported satisfaction with $\mathrm{KC}$ at birth and in the first 3 postpartum days. ${ }^{[13]}$ Thus, the purposes of the two case studies reported here were to document clinical experience using $\mathrm{KC}$ in newborns with NAS to determine how holding impacted severity of NAS by documenting changes in Modified Neonatal Abstinence scores and how mothers felt about $\mathrm{KC}$. We wanted to observe how long the mother spontaneously offered $\mathrm{KC}$ because mothers who are smokers might not be able to tolerate an hour or more of $\mathrm{KC}$ and because mothers on drug maintenance programs may be reluctant to visit or hold their newborns skin-to-skin as previous research has shown. ${ }^{[12]}$

\section{METHOD}

In this Level II Neonatal Special Care Unit (NSCU) with 16 private (single-bed) rooms, $88 \%$ of all healthy term newborns receive Birth KC. ${ }^{[14]}$ Maternal-infant skin-to-skin contact for 1-2 hours beginning immediately after birth and staying skin-to-skin until the first feeding at breast is completed. Mothers provided continuous $\mathrm{KC}$ except when taking bathroom breaks or when the newborns needed their diapers changed or nurses wanted the infant returned to the crib for vital signs and assessments. One mother provided $\mathrm{KC}$ twice (Case \#1) and the other provided $\mathrm{KC}$ over four consecutive nights (Cases \#2). During KC, infants were kept beneath two receiving blankets folded in half and then folded into triangles placed about 3 inches below the shoulders so the infant's arms and legs could be easily extracted and visualized for jitteriness and clonic movement assessment for Modified Neonatal Abstinence Scoring (MNAS). Modified Neonatal Abstinence Scores were measured every 4 hours by NICU staff nurses who had been trained up to 0.90 reliability. The Modified Neonatal Abstinence Scoring System was used to evaluate severity of NAS. ${ }^{[15,16]}$ The Modified Neonatal Abstinence Scoring System is a more comprehensive instrument than the earlier version that appeared in $1975^{[17]}$ assigning a cumulative score based on observations over time of 21 items relating to signs of neonatal withdrawal. The MNAS is routinely scored with every feeding/vital signs assessment (every 4 hours for term infants) and can be rescored one hour after medication administration at the discretion of the nurses. The reliability of the MNAS is reported to be 0.88 with trained nurses, ${ }^{[18]}$ and the concurrent validity was established with 121 infants on the original version. ${ }^{[17]}$

While the mother was conducting $\mathrm{KC}$, the mother and the baby were intermittently but regularly observed to make sure

Published by Sciedu Press that their conditions were satisfactory. These observations and the feedback from the staff nurse caring for the infants enabled evaluation of infant behavior (awake, asleep, agitated, calm, relaxed, etc) during KC. Maternal responses to $\mathrm{KC}$ were obtained when mothers were verbally asked how they felt about doing $\mathrm{KC}$ with their newborns. Institutional review board approval and consents from the mothers were obtained.

All NAS newborns were managed by one neonatologist and in this unit, MNAS was measured every four hours and medication (fentanyl, morphine, phenobarbital, or clonidine) was given every four hours as ordered by the neonatologist to keep MNAS score <9.0. If the MNAS scores was $>8$, medication, usually fentanyl, was initiated or increased until a plateau of scores $<9$ was reached. The newborn is stabilized on this dose for 48 hours until all MNAS scores were $<9$ for 48 hours and then gradually weaned. If MNAS score was $\geq 8$, weaning was postponed and re-escalation (i.e. if newborn requires more medication for increasing MNAS scores once stabilized) began. At the time that of the case studies, the standard of care in medicating NAS infants was the Johns Hopkin's Hospital standardized medication regime using morphine for treatment of NAS.

\section{Results}

\subsection{Results for case \#1}

The Caucasian mother was 21 years old when she delivered a breech female by primary cesarean section at 6:30 p.m. at $38 \& 1 / 7$ weeks gestation because of meconium-stained amniotic fluid and decreased fetal heart tone rate. The mother had some college education and began prenatal care at 18-19 weeks gestation for this, her third pregnancy and second live birth. She gained 22 pounds and smoked during pregnancy, denied alcohol use, and a urine toxicology screen on the day of delivery was positive for oxycodone. The mother related that she was taking a friend's Percocet pills for back pain, and that she also took Tylenol with codeine during pregnancy. The mother did not want to breastfeed, but provided expressed breast milk for all newborn feedings during the days of observation.

\subsubsection{First day of life}

The newborn daughter weighed 2,540 grams, had APGARS of 6 and 9 at 1 and 5 minutes respectively, had a Ballard score equivalent to 39 weeks gestation, and was small for gestational age. After resuscitative efforts and newborn care in the operating room, the newborn was admitted directly to the NSCU at 22 minutes of life for continuing respiratory distress marked by tachypnea and retractions. Vital signs upon admission were heart rate of 147 , respiratory rate of 72 , and a skin temperature of $97.2^{\circ} \mathrm{F}$. She was placed under 
radiant warmer and maintained temperature stability between $97.6^{\circ} \mathrm{F}$ and $98.8^{\circ} \mathrm{F}$. She was placed under an oxygen hood at $100 \%$ oxygen and her $\mathrm{SaO}_{2}$ stabilized at values $>95 \%$ within minutes. Her admission chest xray showed bilateral pulmonary infiltrates consistent with meconium aspiration. She also had umbilical lines placed and unit policy was that no holding of the infant is allowed on the day of placement of umbilical lines. Three and a half hours post-birth her initial MNAS was 11 (changes across the day are in Figure 1) and her temperature was $98.8^{\circ} \mathrm{F}$. At this time she showed an element of Persistent Pulmonary Hypertension of the Newborn. A fentanyl bolus of $0.5 \mathrm{mcg} / \mathrm{kg}$ was given and was followed by a fentanyl drip that started at $0.5 \mathrm{mcg} / \mathrm{kg} / \mathrm{hr}$. Twenty minutes after the drip was started her MNAS was 13, and four hours later the MNAS was 10, and then climbed to 15 nearly four hours later. Another bolus of fentanyl $(1.0 \mathrm{mcg} / \mathrm{kg})$ was given and the fentanyl drip was increased to $1.0 \mathrm{mcg} / \mathrm{kg} / \mathrm{hr}$. Four hours later the newborn's MNAS was 13, and another fentanyl bolus $(1.5 \mathrm{mcg} / \mathrm{kg})$ was administered and the fentanyl drip was increased to $1.5 \mathrm{mcg} / \mathrm{kg} / \mathrm{hr}$, resulting in a drop to 12 for the MNAS two hours later. Both parents had visited their daughter five times and had touched her as she lay in her bed, providing only touch because holding was prohibited. Visits and hand touch had no apparent effect on MNAS which showed a pattern of high values varying between 10 to 15 on Day 1 (see Figure 1). Three bolus doses of fentanyl had been given to augment the low dose fentanyl drip which, 16 hours after it began, was increased from $0.5 \mathrm{mcg} / \mathrm{kg} / \mathrm{hr}$ to $1.5 \mathrm{mcg} / \mathrm{kg} / \mathrm{hr}$ on the first day.

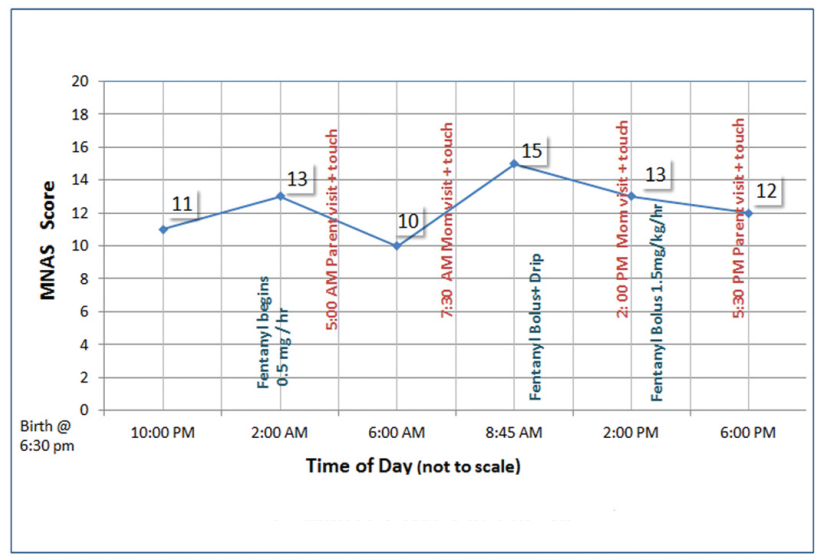

Figure 1. Subject 1 day 1 of life no $\mathrm{KC}$

\subsubsection{Second day of life}

At the beginning of her 2nd day of life, MNAS rose to 12 at 6:50 p.m. KC was given for one hour and ten minutes from 10:00-11:10 p.m. and the newborn appeared to sleep. The MNAS taken during $\mathrm{KC}$ was 3, and remained at 3 until 09:30 a.m. when MNAS rose to 6 and then dropped to 5 at
2:00 p.m., and was again 5 another four hours later. Throughout the remainder of Day 2 MNAS were 3-6. Thus, MNAS scores dropped during $\mathrm{KC}$ and remained low for the rest of Day 2. The newborn received no boluses of fentanyl but was maintained on $1.5 \mathrm{mcg} / \mathrm{kg} / \mathrm{hr}$ fentanyl drip throughout Day 2 (see Figure 2).

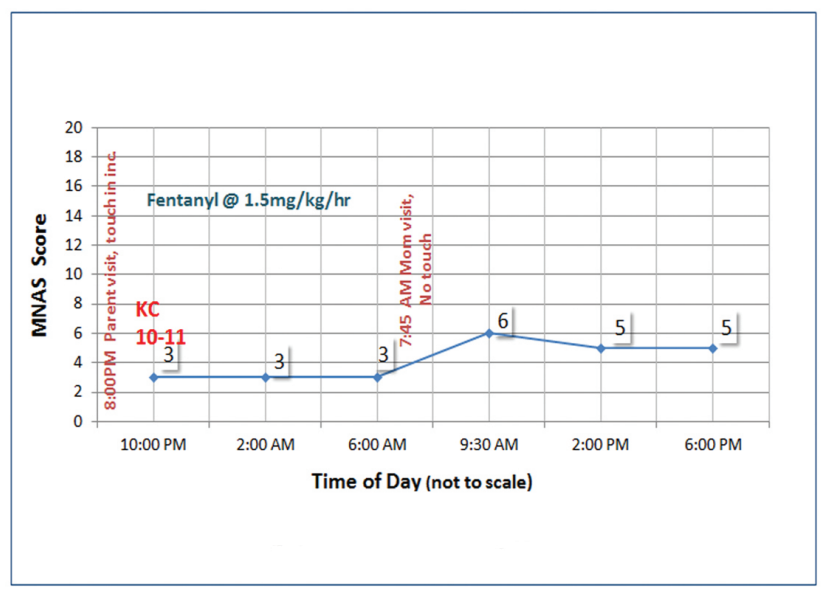

Figure 2. Subject 1 day 2 of life with KC

\subsubsection{Third day of life}

At 6:30 p.m., as the 3rd day of life began, the newborn's MNAS was 5, and at 10:30 p.m. it was 6 (see Figure 3). The newborn was started on a nasal cannula at 0.5 liters per minute of $100 \%$ oxygen because of tachypnea. At two a.m. the mother started a one hour session of $\mathrm{KC}$ and the newborn quickly calmed and appeared drowsy. At 2:30 a.m. the MNAS was 7. Three hours after KC stopped, the MNAS had risen to 10 , mandating a fentanyl bolus of $2.0 \mathrm{mcg} / \mathrm{kg}$ that brought the MNAS down to 7 forty minutes later. Nonetheless, at 6:45 a.m., even with an MNAS below the cut off value of " 8 ", the fentanyl drip was increased to $2.0 \mathrm{mcg} / \mathrm{kg} / \mathrm{hr}$ for treatment of agitation and continuing respiratory distress. An echocardiogram showed patent foramen ovale. Intubation occurred at 7:05 a.m. due to climbing $\mathrm{PCO}_{2}$ values (48\%-57\%) and increased work of breathing; the fentanyl drip was once again increased to $4.0 \mathrm{mcg} / \mathrm{kg} / \mathrm{hr}$. Throughout the remainder of Day 3, MNAS was 6 and the newborn continued to be irritable when undisturbed, and was agitated when being given care, necessitating changes in medication that kept the MNAS scores $<8$. In summary for Day $3, \mathrm{KC}$ was given once for 60 minutes and three hours after $\mathrm{KC}$ stopped the newborn's MNAS score had raised to 10. Intubation is rarely required for MNAS symptoms, but intubation was necessary for the infant's respiratory distress. Intubated infants receiving fentanyl usually require higher ventilator rates and peak inspiratory pressures 24 hours after intubation. Because the infant had increasing fentanyl doses and required intubation, 
adverse respiratory function, no doubt, affected the infant's severity of NAS.

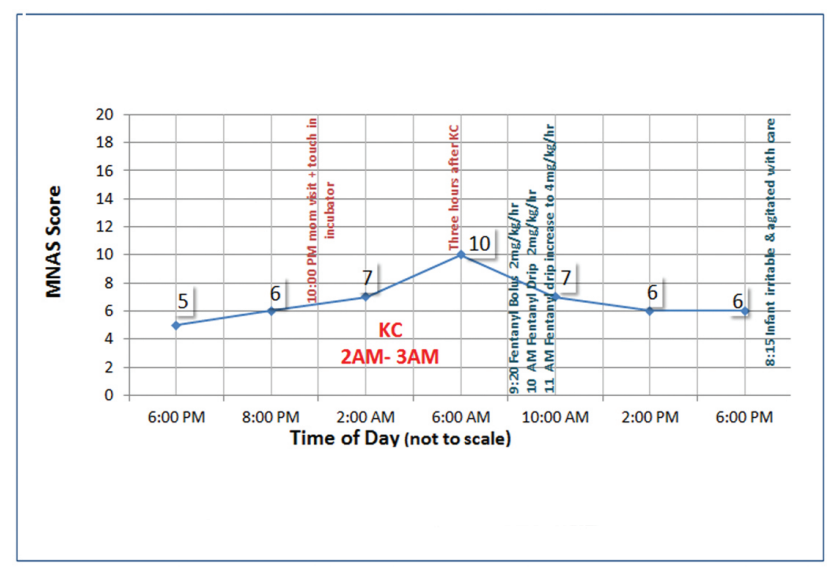

Figure 3. Subject 1 day 3 of life with $\mathrm{KC}$

\subsubsection{Fourth day of life}

The mother visited once and touched her newborn with her hand, but did not give any $\mathrm{KC}$ because she said she was feeling ill. Shortly thereafter the mother was admitted to intensive care for puerperal complications and remained in intensive care for several days. The newborn's NAS scores were 5 throughout Day 4 as the high fentanyl drip of $4.0 \mathrm{mcg} / \mathrm{kg} / \mathrm{hr}$ continued. The severity of NAS increased and the newborn was converted to morphine treatment. Six weeks later, the newborn was still receiving morphine therapy and had not begun weaning. The newborn was transferred to child protective services for custody at discharge because the mother had recently been convicted of physical abuse of her first child.

\subsubsection{Summary of case study \#1 results}

MNAS scores decreased from 12 to 3 during the first KC session which occurred on Day 2 and remained low for the remainder of Day 2 of life. The infant was obviously experiencing significant respiratory distress on Day 2 when supplemental oxygenation by nasal cannula began. MNAS $<8$ could have been due to increased fentanyl drip dosage to manage respiratory distress and respiratory distress' concomitant physiologic instability and behavioral restlessness. On Day 3 of life, the newborn's MNAS rose by one point during $\mathrm{KC}$ and continued to rise after $\mathrm{KC}$ until an increased dose fentanyl was given. On Day 3 when $\mathrm{KC}$ started the infant was on nasal cannula for supplemental oxygenation and was later switched to assisted ventilation by intubation. Thus, the precursor to MNAS changes is unknown. If $\mathrm{KC}$ was associated with reduced MNAS on Day 2, one would expect MNAS on Day 3 to be reduced too, but the scores were not. Instead, MNAS increased, probably due to respiratory distress marked by high $\mathrm{PCO}_{2}$ and low $\mathrm{PO}_{2}$ values, suggesting that $\mathrm{KC}$ did not have a role in reducing MNAS, or at least not a consistent role. MNAS increases may have also been due to the infant's small-for-gestational age status (SGA). SGA infants have irritability, state instability and delayed neurobehavioral maturation and competency ${ }^{[22]}$ and are more likely to have abnormal and delayed sucking development than appropriate-for-gestational age infants ${ }^{[23]}$ and feeding is a MNAS item, physiologic instability, increasing respiratory distress, and use of fentanyl (fentanyl administration does create NAS symptomatology ${ }^{[24]}$ ). Thus, the effects of $\mathrm{KC}$ alone or $\mathrm{KC}$ in conjunction with fentanyl medication to reduce NAS symptomatology in this infant are not known.

\subsection{Results for case \#2}

A 28 year old G2 P1 Caucasian woman who attended the 12 th grade but did not graduate, began prenatal care at 28 weeks gestation, gained 62 pounds, smoked throughout pregnancy, and denied use of alcohol, but admitted to use of heroin for the first five months of pregnancy and smoking throughout pregnancy. Maternal urine toxicology screen at 28 weeks gestation was positive for opiates, codeine, morphine, oxycodone, cocaine, and marijuana. Buprenorphine treatment began at 29 weeks gestation. Buprenorphine is an opioid medication that has been increasingly used since 1996 in the United States for antenatal management of substance abuse, because it is efficacious in preventing maternal relapse to illicit opioid use in opioid-dependent pregnant women. ${ }^{[19]}$ Between $21 \%$ and $85 \%$ of buprenorphineexposed newborns will develop NAS. ${ }^{[5,20]}$ The severity of NAS in buprenorphine-exposed infants can vary between mild (with few infants needing treatment), and severe (with $91 \%$ of infants needing medication treatment). ${ }^{[3,5]}$ A recent review has shown that fetal cardiac and motor functioning is better, NAS is less severe ${ }^{[19]}$ and neonatal length of stay is shorter ${ }^{[21]}$ in buprenorphine-exposed infants than in methadone-exposed infants. The day before delivery the maternal urine toxicology screen was positive for buprenorphine. The mother was taking prescribed buprenorphine 24 $\mathrm{mg} /$ day at the time of delivery. The mother wanted to breastfeed but had flat nipples, so she expressed breast milk for all newborn feedings during the observation period. During long sessions of $\mathrm{KC}$, newborns were removed from $\mathrm{KC}$ to have diapers changed, vital signs taken, and to be fed. MNAS was conducted while the newborn remained in $\mathrm{KC}$.

\subsubsection{First day of life}

A spontaneous vaginal delivery produced a 3,180 gram female at 39 weeks gestation, was appropriate weight for gestational age and had APGARS of 8 and 9 at 1 and 5 minutes respectively. Within one minute of birth the newborn was placed in $\mathrm{KC}$ and remained undisturbed in $\mathrm{KC}$ for 80 minutes. 
The newborn's condition in KC was monitored by a neonatal nurse practitioner (NNP). One and a quarter hours post-birth the newborn's vital signs were heart rate 150 , respiratory rate 80 , skin temperature $97.8^{\circ} \mathrm{F}$ as the newborn remained calm and sleepy. Because of the high respiratory rate, the MNAS was taken and was 9. At 80 minutes post-birth, $\mathrm{KC}$ was stopped and the newborn was taken to an open-air crib in the Neonatal Special Care Unit. Newborn urine and meconium screens were negative, but were not tested for buprenorphine. One hour later (when 2 hrs, 20 minutes old), the MNAS was 11 and morphine $0.04 \mathrm{mg}$ was started orally. Five hours later the MNAS was 12; four hours later the MNAS was 10 and the maintenance morphine dose of $0.04 \mathrm{mg}$ po was administered. MNAS decreased to 8 within one hour, but, was 10 three hours later. Another maintenance dose of morphine $0.04 \mathrm{mg}$ po was given with a one-hour rescore of 8 . Three hours later the MNAS was again 10. The maintenance dose of morphine $0.04 \mathrm{mg}$ po was given and the one-hour rescore was again 8 . Three hours later the MNAS was 19, so another maintenance dose of morphine $0.04 \mathrm{mg}$ po was given. Because the onehour rescore was 17 rescue dose of morphine $(0.06 \mathrm{mg} \mathrm{po})$ was given and the maintenance dose was increased to $0.1 \mathrm{mg}$. One hour later the mother held her swaddled newborn for 75 minutes; 45 minutes after swaddled holding stopped, the MNAS was 16 and the increased dose of morphine $(0.1 \mathrm{mg}$ po) was given. On Day One, eighty minutes of $\mathrm{KC}$ failed to prevent the MNAS from rising above the cut-off value of 8 . After $\mathrm{KC}$ for the first 80 minutes of life, no further $\mathrm{KC}$ was given during the first day of life, and a pattern of increasing MNAS resulted in an increase in morphine dose from $0.04 \mathrm{mg}$ to $0.10 \mathrm{mg}$. Six doses of morphine had been given. Vacillating MNAS above the cut off value of 8 was the predominant pattern on the first day of life (see Figure 4).

\subsubsection{Second day of life}

On Day 2 at 1:20 p.m. MNAS was still high, so a rescue dose of morphine $0.12 \mathrm{mg}$ po was administered. At 1:50 p.m. the mother held her swaddled newborn for 40 minutes. Two hours later (4 p.m.) the MNAS was 16 and the new maintenance dose of morphine $0.12 \mathrm{mg}$ po was given. One hour later (5 p.m.) the NAS was 17; a rescue dose (0.06 mg po) of morphine was given. Three hours later $(8$ p.m.) the NAS score was 9 , and the new maintenance dose of $0.18 \mathrm{mg}$ po of morphine was administered. Fifty minutes after this last dose (at 8:50 p.m.), the mother started $\mathrm{KC}$ and continued $\mathrm{KC}$ for two hours until 10:50 p.m. The MNAS ten minutes after $\mathrm{KC}$ started (and one hour after the last dose of morphine) was 2. Seventy minutes after KC ended (12 Midnightc), the MNAS was 12 and $0.18 \mathrm{mg}$ po of morphine was again given. The mother returned and started $\mathrm{KC}$ at 1 a.m.- as soon as vital signs were complete; $\mathrm{KC}$ continued for 5.25 hours (until
6:25 a.m.) and the newborn slept throughout $\mathrm{KC}$ except for one awakening for an anticipated feeding which was conducted in $\mathrm{KC}$. The MNAS was 4 when taken one, four, and five hours into $\mathrm{KC}$. The MNAS score at $2^{3 / 4}$ hours (9:10 a.m.) after $\mathrm{KC}$ ended was 5. The newborn then received maintenance morphine $0.18 \mathrm{mg}$ po. About three hours later (at noon which was also $5^{1 / 2}$ hours after $\mathrm{KC}$ had ended), the MNAS was 9 and one hour after that (at 1 p.m.) the NAS was 5. When diapering needed to be performed during $\mathrm{KC}$, the newborn was removed from $\mathrm{KC}$, placed in the crib where MNAS was done, diapering, and feeding occurred. The newborn was then immediately returned to KC. On Day 2 , the morphine dose increased from $0.10 \mathrm{mg}$ to $0.18 \mathrm{mg}$, was administered 7 times, and MNAS ranged between 5-17 in the absence of $\mathrm{KC}$. The MNAS during $\mathrm{KC}$ were between 2 and 4, rose to 5 three hours after $\mathrm{KC}$ ended, and continued rising to a score of 9 seven hours after $\mathrm{KC}$ ended (see Figure $5)$.

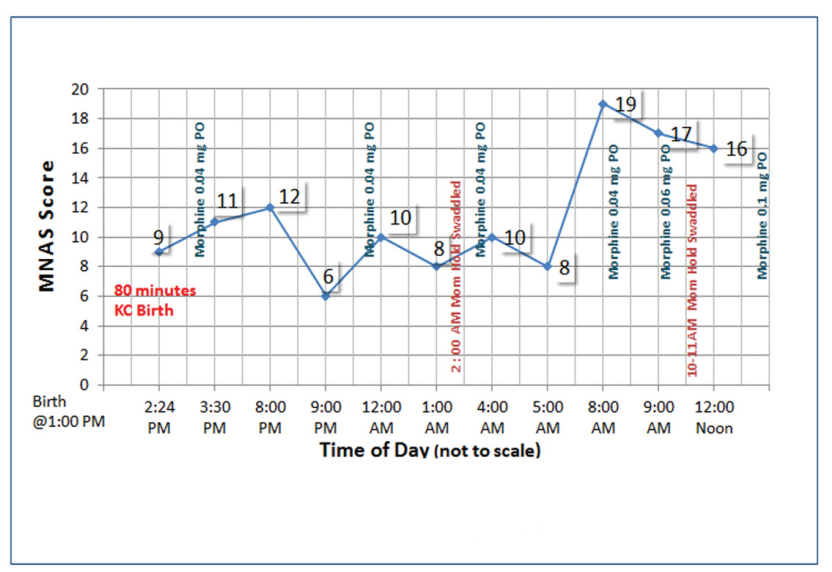

Figure 4. Subject 2 day 1 of life $\mathrm{KC}$ at birth

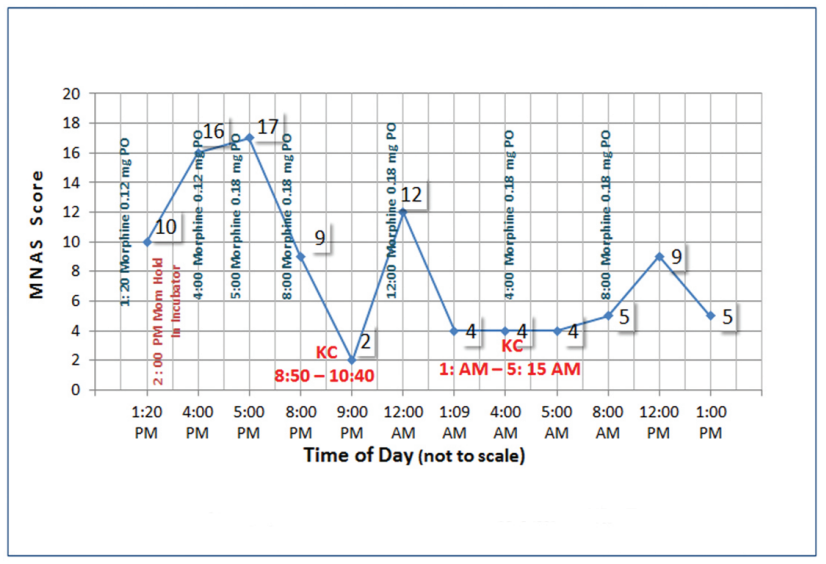

Figure 5. Subject 2 day 2 of life with $\mathrm{KC}$ 


\subsubsection{Third day of life}

On Day 3, two MNAS about 4 hours apart were 5 and 8 respectively (at 4 p.m. and 7:45 p.m.), and morphine 0.18 $\mathrm{mg}$ po was administered both times. About three hours later, the mother began a 7.5 hour session of $\mathrm{KC}$ and again the newborn remained predominantly asleep and had minimal agitation when awake for two feedings. MNAS 1 hour (12 $\mathrm{MN}$ ) and 4 hours ( 4 a.m.) after KC began were 3 and 5 respectively. Morphine $0.18 \mathrm{mg}$ was given for both MNAS. At 8 a.m. (1 hour after $\mathrm{KC}$ ended), the mother began swaddled holding and her newborn's MNAS was 6 (morphine 0.18 $\mathrm{mg}$ was again given). The mother continued swaddled holding for another 3.5 hours and MNAS was 13 (11:30 a.m.); morphine $0.18 \mathrm{mg}$ po was given. The next MNAS one hour later (12:30 p.m.) was 6 (see Figure 6). On Day 3 of life, the morphine dose remained at $0.18 \mathrm{mg}$ po every four hours and was administered 6 times. MNAS ranged between 5 and 8 before $\mathrm{KC}$, ranged between 3 and 5 during $\mathrm{KC}$, and between 6-13 after $\mathrm{KC}$ and during swaddled holding. The mother provided seven and a half hours of $\mathrm{KC}$, during which the infant slept before and after one MNAS, feeding and diapering episode. The mother also slept during $\mathrm{KC}$, taking food, a drink of water and a bathroom break while her infant was being observed for MNAS, having vital signs taken, fed, and diapered.

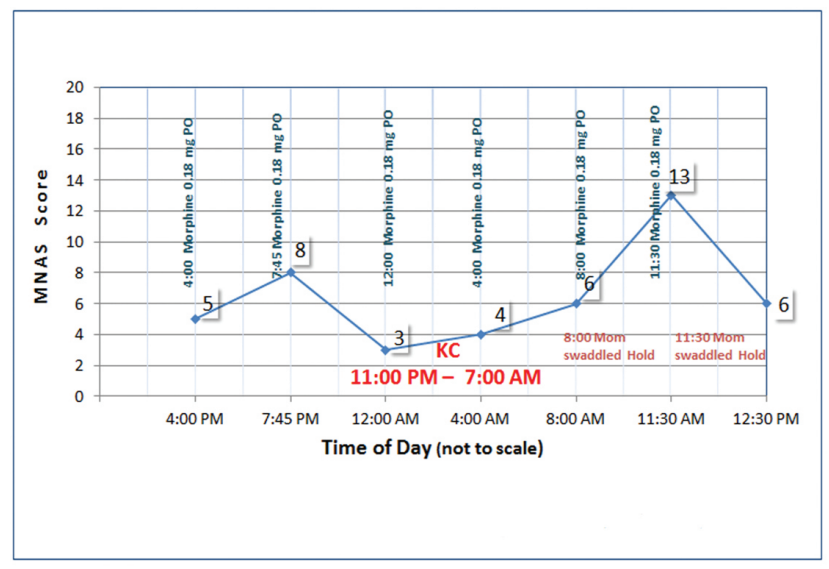

Figure 6. Subject 2 day 3 of life with KC

\subsubsection{Fourth day of life}

The first MNAS of Day 4 was at 3:00 p.m. and was 8; morphine $0.18 \mathrm{mg}$ po was given. Four hours later (at 7:15 p.m.) MNAS was 9 and morphine $0.18 \mathrm{mg}$ po was given. At 8:00 p.m., 45 minutes after having a MNAS of 9 at 7:15 p.m., the mother began 11 hours of $\mathrm{KC}$ throughout the night. The newborn appeared to be sleeping at each observation when in $\mathrm{KC}$ and was relatively motionless during $\mathrm{KC}$. The first MNAS during $\mathrm{KC}$ was obtained 30 minutes after $\mathrm{KC}$ had started and was 2, four hours later (12 Midnight) MNAS in $\mathrm{KC}$ was 3 and the mother, who had fallen asleep about 10:30 p.m, awakened for the MNAS assessment, feeding and diapering of her infant in KC. Then the mother went back to sleep. The mother awakened just before 4 a.m. and fed her infant in KC before the MNAS was taken in the open air crib and was scored as a 3 while the mother took a short bathroom break. Whenever the mother and infant slept in $\mathrm{KC}$, a staff nurse monitored the pair for safe positioning and cardiorespiratory stability.

KC ended at 7:00 a.m. At 8:00 a.m. The MNAS was 6; four hours later at noon MNAS was 7 (see Figure 7). On Day 4, the maintenance dose of morphine $0.18 \mathrm{mg}$ po was given every four hours. The MNAS before KC were 8 and 9, and during 11 hours of $\mathrm{KC}$ were 2 to 3 . Within one hour after $\mathrm{KC}$ stopped, the MNAS score had risen from 3 to 6 and rose again to 7 four hours later even though morphine was being given with the same frequency and dose.

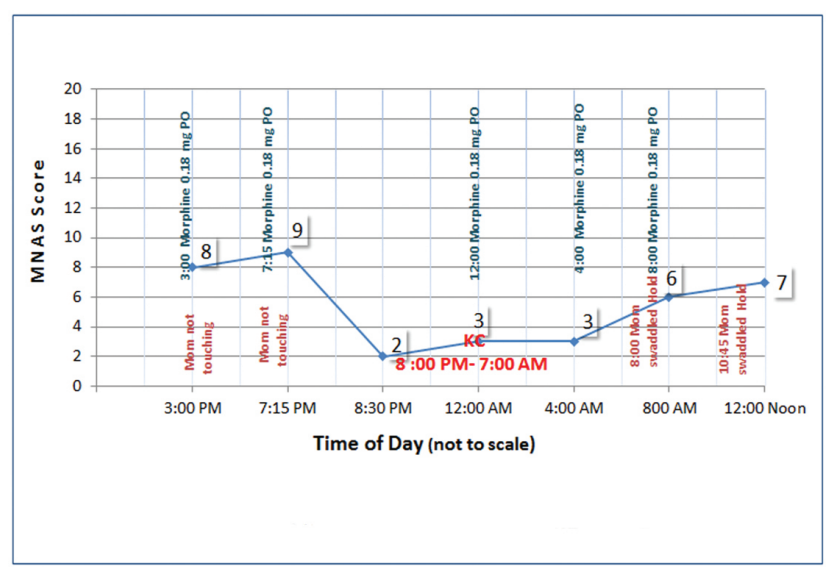

Figure 7. Subject 2 day 4 of life with $\mathrm{KC}$

\subsubsection{Fifth day of life}

The fifth day of life began at 4:00 p.m. with MNAS equal to 8 ; morphine $0.18 \mathrm{mg}$ po was continued. One hour later (2:00 p.m.), the NAS dropped to 3, but climbed up to 12 four hours later (6:00 p.m.) with a one hour rescore of 4 by 7:00 p.m. Then the MNAS rose and fell repeatedly throughout most of the day, up until the last 5 hours (8:00 a.m to 1:00 p.m). At 8:00 AM, the newborn's MNAS was 11 , morphine $0.18 \mathrm{mg}$ po was given and the mother began 30 minutes of $\mathrm{KC}$. Newborn behavior during $\mathrm{KC}$ was not reported. Thirty minutes after $\mathrm{KC}$ ended (one hour after the 9:00 a.m. morphine), the MNAS was 5 and declined to 4 four hours later (1:00 p.m.). Throughout Day 5, morphine $0.18 \mathrm{mg}$ po was given every four hours, MNAS ranged between 3 to 14 without KC. After $\mathrm{KC}$, MNAS dropped from 11 to 5 .

For the remainder of the newborn's hospitalization, the mother repeatedly conducted KC (infant was fed and scored 
and diapered in $\mathrm{KC}$ ) for about 4-6 hours per day. The mother reported so much satisfaction with $\mathrm{KC}$ that she said she would continue $\mathrm{KC}$ at home. Her newborn was discharged to her care two weeks after the case study began. Post-discharge follow-up reports were not available for review.

\subsubsection{Summary of case study \#2 results}

On the first day of life, the baby got only 80 minutes of birth $\mathrm{KC}$, MNAS were above the value of 8 during the whole day which resulted in increasing the morphine dose from $0.04 \mathrm{mg}$ to $0.10 \mathrm{mg}$, the baby got a total of six doses of morphine during the first day of life. On the second day of life, the baby got a total of 7.25 hours of $\mathrm{KC}$, morphine dose increased from $0.10 \mathrm{mg}$ to $0.18 \mathrm{mg}$ and got a total of seven doses during day two. During KC, MNAS ranged between 2 to 4 and in absence of $\mathrm{KC}$, MNAS ranged between 5 to 17. On the third day of life, the baby got 7.5 hours of $\mathrm{KC}$, morphine dose remained at $0.18 \mathrm{mg}$ every four hours. During $\mathrm{KC}$, MNAS ranged between 3 to5 and in the absence of $\mathrm{KC}$, MNAS ranged between 5 to 13 . On the fourth day of life, the baby got 11 hours of $\mathrm{KC}$, morphine dose were maintained at $0.18 \mathrm{mg}$ every four hours. During KC, MNAS were between 2-3 and in the absence of KC, MNAS were between 6 to 9 . On the fifth day of life, the baby got 30 minutes of $\mathrm{KC}$, morphine dose remained at $0.18 \mathrm{mg}$ every four hours, MNAS ranged from 3-14 without KC. After the 30 minutes KC, MNAS dropped from 11 to 5 .

\section{Discussion}

Two substance-abusing mothers provided Kangaroo Care to their newborns for varying amounts of time over the first 3-5 days post-birth. For both newborns on the first day post-birth, severity of NAS scores remained above 8 when KC was not given. Severity of neonatal abstinence syndrome did not appear to diminish when $\mathrm{KC}$ was provided for 60-80 minute epochs, but NAS scores remained $<8$ (scores were 2-6) when $\mathrm{KC}$ was given for three or more hours and then rose within an hour of $\mathrm{KC}$ being terminated. During KC newborns appeared to be calm and sleeping, which differs greatly from nearly constant agitation occurs when newborns are conventionally treated. Calm sleeping in the newborns is also important because both mothers were smokers, and maternal smoking is associated with decreased parasympathetic control in newborns (so newborns are more agitated under sympathetic influences) and more severe NAS symptomatology. ${ }^{[25]}$

Each of the mothers provided different amounts of KC. Case \#1 mother provided 60-70 minutes per day for each of two days, and Case \#2 mother provided 30 minutes-11 hours/day over the first five days of life, commonly providing 7-11 hours of consecutive, uninterrupted KC on Days 2, 3, and 4 post-birth usually at night. The long duration of $\mathrm{KC}$ pro- vided by Case \#2 mother is an important observation because substance abusing mothers commonly visit only for a short period time, so $\mathrm{KC}$ oxytocin influences in the mother may increase the duration of $\mathrm{KC}$ sessions and visits by substanceabusing mothers, as it does in non-substance abusing mothers. ${ }^{[26]}$ Another unexpected observation was that neither mother left $\mathrm{KC}$ to have a smoke even though both were smokers during pregnancy and one mother provided seven or more hours of $\mathrm{KC}$ in several sessions. Also, morphine was given every four hours once started and did not appear to reliably maintain a low NAS value as $\mathrm{KC}$ did when started with or shortly after the morphine dose, suggesting that $\mathrm{KC}$ may be an effective adjuvant therapy to morphine for management of NAS severity. Morphine therapy is not without risk because newborns have had seizures when morphine treatment has been stopped. ${ }^{[19]}$

The vacillating Modified Neonatal Abstinence Scoring System scores that were demonstrated by both newborns were expected because NAS expression is widely variable among affected newborns and the reason for this variability is largely unknown because mechanisms that predispose newborns to NAS expression are not understood. One theory that has been proposed is that behaviors of drug exposed newborns are manifested in dysfunctional vagal regulation of autonomic processes: ${ }^{[25]}$ newborns with lower parasympathetic regulation have higher NAS symptomatology. But, KC causes dominant parasympathetic neuroregulation ${ }^{[26-29]}$ due to central oxytocin release ${ }^{[29]}$ and the upright head tilt position. ${ }^{[30]}$ $\mathrm{KC}$ also stabilizes vagally-controlled autonomic processes in newborns. ${ }^{[31]} \mathrm{KC}$ is known to improve many of the adverse symptoms characterizing NAS, i.e. irritability, poor sleep, poor state regulation, and stress. For example, irritability and crying are common in NAS newborns but are diminished and practically non-existent during $\mathrm{KC}^{\text {; }}{ }^{[32]} \mathrm{NAS}$ newborns have very poor sleep and difficulty with state regulation, ${ }^{[33]}$ but both sleep quality and state regulation improve dramatically in $\mathrm{KC}$ as compared to out-of $\mathrm{KC} ;{ }^{[34,35]}$ and NAS newborns exhibit a great deal of stress ${ }^{[36]}$ and stress is reduced by $70 \%$ within 20 minutes of KC onset. ${ }^{[37-39]}$ Two other mechanisms may have decreased NAS severity in the Case Study \#2 newborn. The first mechanism is feeding because feeding increases oxytocin ${ }^{[40]}$ and cholescystokinin release; ${ }^{[41]}$ both of these neuropeptides promote relaxation and sleep. ${ }^{[42]}$ The second is provision of breast milk which may contain trace amounts of opiates (i.e. methadone, buprenorphine, etc) to which the mother has been exposed and which may calm the newborn, too. Though the amount of opiate being transferred in breast milk is very slight, ${ }^{[43]}$ the possibility of breast milk opiate reducing severity of NAS has been suggested by studies showing that breast milk-fed infants have lower NAS 
scores than formula- fed infants. ${ }^{[44]}$

\section{Conclusion}

The results clearly suggest that KC should be tested as a non-pharmacologic treatment for NAS severity. Finding an effective non-pharmacologic treatment is important because use of morphine has many risks, ${ }^{[20]}$ sedatives are not really safe to use according to a recent Cochrane review, ${ }^{[45]}$ and current non pharmacologic treatments have not modified the duration, intensity, and frequency of NAS symptoms. ${ }^{[46]}$ Further, $\mathrm{KC}$ is readily available when mothers are available and involves the mother in her infant's care, and may be effective in reducing severity of NAS symptomatology. Recent clinical observations at Grant Medical Center in Columbus, $\mathrm{OH}$ have revealed that the number of infants of substance abusing mothers being transferred to the NSCU for NAS has decreased approximately $67 \%$ since $\mathrm{KC}$ at birth has been routinely practiced because mothers spontaneously continue $\mathrm{KC}$ during the postpartum hospitalization and Modified Neonatal Abstinence Scoring System scores have not reached the cut off value necessitating pharmaxcologic intervention. ${ }^{[47]}$ Kangaroo Care may indeed meet the need for effective nonpharmacologic interventions as identified in the literature. ${ }^{[35]}$

To rigorously measure $\mathrm{KC}$ effects on NAS severity, Modified Neonatal Abstinence Scoring should occur immediately prior to transfer into $\mathrm{KC}$ and ideally, during the last minute of a $\mathrm{KC}$ session to really reflect KC's influence rather than reflecting the physiologic and behavioral disorganization that occurs with transfer into and out of KC. ${ }^{[48]}$ In addition, newborn medication dosage and frequency need to be considered covariates in statistical analyses to differentiate $\mathrm{KC}$ effects from medication effects. Similarly, the time and dosage of the mother's last substance use prior to birth and the number of substances to which the newborn was exposed need to be statistically controlled as well. Poly-drug exposure (and cocaine in particular) is associated with lower parasympathetic neuroregulation and greater severity of NAS symptoms. ${ }^{[19]}$ Development and testing of a standardized procedure for Modified Neonatal Abstinence Scoring System scoring during $\mathrm{KC}$ needs to be undertaken, too.

\section{REFERENCES}

[1] Hudak ML, Tan RC. The committee on drugs, the committee on fetus and newborn. Neonatal drug withdrawal. Pediatr. 2012 Jan; 129: e540-560. http://dx.doi.org/10.1542/peds. 2011-3212

[2] Patrick SW, Schumacher RE, Benneyworth BD, et al. Neonatal abstinence syndrome and associated care expenditure: US 20002009. J Amer Med Assoc. 2012 May; 307(18): 1934-1940. http: //dx.doi.org/10.1001/jama.2012.3951

[3] Kakko J, Heilig M, Sarman I. Buprenorphine and methadone treatment of opiate dependence during pregnancy: comparison of fetal growth and neonatal outcomes in two consecutive case series. Drug Alcohol Dependence. 2008 Jul; 96(1-2): 69-78.

[4] Kahila H, Saisto T, Kivitie-Kallio S, et al. A prospective study on buprenorphine use during pregnancy: effects on maternal and neonatal outcome. Acta Obstet Gynecol Scand. 2007 Jan; 86(2): 185-190. PMID:17364281. http://dx.doi.org/10.1080/00016340601 110770

[5] Kayemba-Kay S, Laclyde JP. Buprenorphine withdrawal syndrome in newborns. A report of 13 cases. Addiction. 2003 Nov; 98(11): 1599-1504. http://dx.doi.org/10.1046/j.1360-0443. 2003 $.00551 . \mathrm{x}$

[6] Sarkar S, Donn SM. Management of neonatal abstinence syndrome in neonatal intensive care unit: a national survey. J Perinatol 2006 Jan; 26(1): 15-17. PMID:16355103. http://dx.doi .org/10 .10 $38 /$ s j.jp. 7211427

[7] Logan BA, Brown MS, Hayes MJ. Neonatal abstinence syndrome: treatment and pediatric outcomes. Clin Obstet Gynecol. 2013 Mar; 56(1): 186-192. http://dx.doi.org/10.1097/GRF.0b013e3 1827 feea 4

[8] Ludington-Hoe SM, Morgan K, Abouelfettoh A. National evidencebased guidelines for Kangaroo Care with preterm infants $>30$ weeks postmenstrual age. Adv Neonatal Care. 2008 May; 8(3 Suppl): S3-
S23. http://dx.doi.org/10.1097/01.ANC.0000324330.257 34. b6

[9] Ludington-Hoe SM. Chapter 18. Kangaroo care is developmental care. In T Verklan, J McGrath (Eds). Developmental Care of Newborns and Infants. 2nd Edition. Louis: Mosby and National Association of Neonatal Nurses; 2010. 245-288 p.

[10] Ludington-Hoe SM. Evidence-based review of physiologic effects of Kangaroo Care. Current Women's Health Reviews. 2011 Aug; 7(3): 243-253. http://dx.doi.org/10.2174/157340411796355162

[11] D'Apolito K. Comparison of a rocking bed and a standard bed for decreasing withdrawal symptoms in drug-exposed infants. MCN, Am J Mat Child Nurs. 1999 May-Jun; 42: 138-144. http: //dx.doi .o $\mathrm{rg} / 10.1097 / 00005721-199905000-00007$

[12] Gale G, Franck L, Lund C. Skin-to-skin (kangaroo) holding of the intubated premature infant. Neonatal Network. 1993 Sep; 12(6): 49-57. PMID:8413138.

[13] Vasquez MJ, Berg OR. The Baby-Friendly journey in a US public hospital. Journal of Perinat Neonatal Nurs. 2012 Jan-Mar; 26(1): $37-$ 46. http://dx.doi.org/10.1097/JPN. Ob013e3182107179

[14] Walters M, Boggs K, Ludington-Hoe SM, et al. Kangaroo Care at birth: Temperature and blood glucose effects. MCN, Am J Mat Child Nurs. 2007 Nov-Dec; 32(6): 375-381. PMID:17968221. http: //dx.doi.org/10.1097/01.NMC.0000298134.39785.6c

[15] Finnegan LP. Neonatal abstinence syndrome: assessment and pharmacotherapy. In: Nelson N, (Ed.) Current Therapy in Neonatal-Perinatal Medicine. 2 ed. Ontario: BC Decker; 1990.

[16] Finnegan LP, Kaltenbach K. Neonatal abstinence syndrome. In: Hoekelman RA, Friedman SB, Nelson N, Seidel HM, (Eds). Primary Pediatric Care. 2 ed. St Louis: C V Mosby; 1992. 1367-78 p.

[17] Finnegan LP, Connaughton JF Jr, Kron RE, et al. Neonatal abstinence syndrome. Assessment and management. Addict Dis. 1975; 2 : 1141-158. 
[18] Walter Z, Christopher R, Wanda W, et al. The Neonatal Withdrawal Inventory: A Simplified Score of Newborn Withdrawal. Journal of Developmental \& Behavioral Pediatrics. 1998 April; 19(2): 67-143.

[19] Jones HE, Finnegan LP, Kaltenbach K. Methadone and buprenorphine for the management of opioid dependence in pregnancy. Drugs. 2012 April; 72(6). http://dx.doi.org/10.2165/11632820-0 00000000-00000

[20] Blazer A, Pulzer F, Knupfer M, et al. Drug withdrawal in newborns clinical data of 49 infants with intrauterine drug exposure: what should be done? Klin Pediatr. 2008 Sep-Oct; 220(5): 308-315. http://dx.doi.org/10.1055/s-2007-992800

[21] Pritham UA, Paul JA, Hayes MJ. Opioid dependency in pregnancy and length of stay for neonatal abstinence syndrome. J Obstet Gynecol Neo Nurs. Mar 2012; 41(2): 180-190. http://dx . doi .org /10.1111/j.1552-6909.2011.01330.x

[22] Mello B, Gagliardo Heloisa, Gonçalves Vanda. Neurodevelopment of small-for-gestational age infants: behavioral aspects in first year. Arq Neuropsiquiatr. 2014 Jul; 72(7): 517-23. PMID:25054984. http://dx.doi.org/10.1590/0004-282X20140096

[23] da Costa SP, van der Schans CP, Zweens MJ a SR, et al. The Development of Sucking Patterns in Preterm, Small-for-Gestational Age Infants. J Pediatr. 2010 Oct; 157(4): 603-9, 609.e1-3. http: //dx.doi.org/10.1016/j.jpeds.2010.04.037

[24] Nancy J. MacMullen, Laura A. Dulski, Paul Blobaum. EvidenceBased Interventions For Neonatal Abstinence Syndrome. Pediatr Nurs. 2014 July-Aug; 40(4): 165-172.

[25] Jansson LM, Dipietro JA, Elko A. Infant autonomic functioning and neonatal abstinence syndrome. Drug Alcohol Dep. 2010 Jun; 109(13): 198-204. http://dx.doi.org/10.1016/j.drugalcdep. 20 10.01.004

[26] Bauer K, Uhrig C, Versmold H. How do mothers experience skin contact with their very immature (gestational age 27-30 weeks), only days old premature infants? Z Geburtshilfe Neonatol. 1999 Nov-Dec; 203(6): 250-254. PMID:10612198.

[27] Bystrova K. Novel mechanism of human fetal growth regulation: A potential role of lanugo, vernix caseosa and a second tactile system of unmyelinated low-threshold C-afferents. Med Hypoth. 2009 Feb; 72(2): 143-146. http://dx.doi.org/10.1016/j.mehy . 20 08.09 .033

[28] Cong X, Ludington-Hoe SM, McCain G, et al. Kangaroo care modifies preterm infant heart rate variability in response to heel stick. Early Hum Dev. 2009 Sep; 85(9): 561-567. http://dx.doi.org /10.1016/j.earlhumdev. 2009.05.012

[29] Feldman R, Singer M, Zagoory O. Touch attenuates infants' physiologic reactivity to stress. Dev Sci. 2010 Mar; 13 (2): 271-278. PMID:20136923. http://dx.doi.org/10.1111/j.1467-7687. 2009.00890.x

[30] Schrod L, Walter J. Effect of head-up tilt position on autonomic function and cerebral oxygenation in preterm infants. Biol Neo. 2002 May; 81(4): 255-259. http://dx.doi.org/10.1159/000056756

[31] McCain G, Ludington-Hoe SM, Swinth JY, et al. Kangaroo Care effects on heart rate variability: A case study. J Obstet Gynecol Neonatal Nurs. 2005 Nov-Dec; 34(6): 689-694. PMID:16282226. http://dx.doi.org/10.1177/0884217505281857

[32] Moore ER, Anderson GC, Bergman N. Early skin-to-skin contact for mothers and their healthy newborn infants. The Cochrane Database of Systematic Reviews. 2007 Jul; 18(3): CD003519. http://dx.doi.org/10.1002/14651858.cd003519.pub2

[33] Sarfi M, Martinsen H, Bakstad B, et al. Patterns in sleep-wakefulness in three-month old newborns exposed to methadone or buprenorphine. Early Hum Dev. 2009 Dec; 85(12): 773-778. http://dx.doi .org /10.1016/j.earlhumdev.2009.10.006
[34] Ludington-Hoe SM, Johnson M, Morgan K, et al. Neurophysiologic assessment of neonatal sleep organization: preliminary results of a randomized controlled trial of skin contact with preterm infants. Pediatr. 2006 May; 117(5): e909-e923. PMID:16651294. http://dx.doi.org/10.1542/peds. 2004-1422

[35] Feldman R. Maternal-infant contact and child development: Insights from the kangaroo intervention. In L'Abate, L. (Editor), Low Cost Approaches to Promote Physical and Mental Health. Theory, Research, and Practice. Springer Publishing Co.: NY, New York City. 2007; 323-351 p. PMID:17717432. http://dx.doi.org/10.10 07/0-387-36899-X_16

[36] Velez M, Jansson LM. The opioid dependent mother and newborn dyad: non-pharmovologic care. J Addict Med. 2008 Sep; 2(3): 113120. http://dx.doi.org/10.1097/ADM.0b013e31817e6105

[37] Collados-Gomez L, Aragones-Corral B, Contreras-Olivares I, et al. Assessing the impact of kangaroo care on preterm infant stress. Enfermeria Clinl. 2011 Mar-Apr; 21(2): 69-74. http://dx.doi.org /10.1016/j.enfcli.2010.12.002

[38] Feldman R, Gordon I, Zagoory-Sharon O. Maternal and paternal plasma salivary and urinary oxytocin and parent-infant synchrony: considering stress and affiliation component of human bonding. Dev Sci. 2011 Jul; 14(4): 752-761. http://dx.doi.org/10.1111/j $.1467-7687.2010 .01021 . \mathrm{x}$

[39] Takahashi Y, Tamakoshi K, Matsushima M, et al. Comparison of salivary cortisol, heart rate and oxygen saturation between early skin-to-skin contact with different initiation and duration times in healthy full term infants. Early Hum Dev. 2011 Mar; 87(3): 151-157. http://dx.doi.org/10.1016/j. earlhumdev.2010.11.012

[40] Borg J, Melander O, Johansson L, et al. Gastroparesis is associated with oxytocin deficiency, oesophageal dysmotility with hyperCCKemia, and autonomic neuropathy with hypergastrinemia. BMC Gastroenterol. 2009 Feb; 25: 9-17. http://dx.doi.org/10.1186/1 471-230X-9-17

[41] Rasoamanana R, Darcel N, Fromentin G, et al. Nutrient sensing and signalling by the gut. Proc Nutr Soc. 2012 Nov; 7(14): 446-455. http://dx.doi.org/10.1017/S0029665112000110

[42] Prospéro-García O, Méndez-Díaz M. The role of neuropeptides in sleep modulation. Drug News Perspect. 2004 Oct; 17(8): 518-522. PMID:15605111. http://dx.doi.org/10.1358/dnp. 2004.17 .8 .863695

[43] Bogen DL, Perel JM, Heisel JC, et al. Estimated infant exposure to enantiomer-specific methadone levels in breastmilk. Breastfeeding Med. 2011 Dec; 6(6): 377-384. http://dx.doi.org/10.1089/b fm. 2010.0060

[44] McQueen KA, Murphy-Oikonen J, Gerlach K, et al. The impact of infant feeding method on neonatal abstinence scores of methadoneexposed infants. Adv Neo Care. 2011 Aug; 11(4): 282-290. http: //dx.doi.org/10.1097/ANC.0b013e318225a30c

[45] Osborn DA, Jeffrey HE, Cole MJ. Sedative for opiate withdrawal in newborn newborns. Cochrane Database Systematic Review, 2010 Oct; 6(10): CD002053.

[46] Raith W, Kutschera J, Muller W, et al. Active Ear Acupuncture Points in Neonates with Neonatal Abstinence Syndrome (NAS). Am J Clin Med. 2011; 39(10): 29-37. PMID:21213396. http: //dx.doi.org/10.1142/S0192415X11008622

[47] Walters M. Personal Communication on Reduction of NAS admissions to NICU from postpartum. April 9, 2012.

[48] Neu M, Browne JV, Vojir C. The impact of two techniques used during skin-to-skin care on the physiologic and behavioral responses of preterm infants. Nurs Res. 2000 Jul-Aug; 49(4): 215 223. PMID:10929693. http://dx.doi.org/10.1097/0000619 9-200007000-00005 